\title{
Effect of Coarse Aggregate Size and Grouting Process on Properties of Preplaced Aggregate Concrete
}

\author{
Kunal Krishna Das ${ }^{1}$, Siu Shu Eddie Lam ${ }^{1}$ \\ ${ }^{1}$ The Hong Kong Polytechnic University, Department of Civil and Environmental Engineering \\ Hung Hom, Kowloon, Hong Kong \\ kunal.k.das@connect.polyu.hk; siu.shu.eddie.lam@polyu.edu.hk
}

\begin{abstract}
Preplaced aggregate concrete (PAC) is produced by first pre-placing the coarse aggregates and then injecting a grout to fill in the voids between the aggregates. This study aims to investigate the effects of coarse aggregate size and grouting process on PAC through experimental study. The effect of flowability and compressive strength of grout is explored. A suitable grout mix is then selected to investigate the effect of different coarse aggregate sizes i.e. $14 \mathrm{~mm}, 20 \mathrm{~mm}, 37 \mathrm{~mm}$ and $45 \mathrm{~mm}$ on the properties of PAC. Effect on PAC using two different grouting processes, namely pumping process and gravity process is investigated. Pumping the grout into preplaced aggregates resulted in lesser void ratio and higher compressive strength. Using $20 \mathrm{~mm}$ size aggregates for production of PAC is recommended to achieve higher compressive strength and better resistance to chloride ion penetration.
\end{abstract}

Keywords: Preplaced aggregate concrete, Aggregate size, Grouting process, Compressive strength, Durability.

\section{Introduction}

Preplaced aggregate concrete ("PAC") is known by various names such as colcrete [1], polcrete [2], two stage concrete [3], prepacked concrete [4], etc. It is different from normal concrete in two fundamental ways, namely method of construction and mix proportion. Firstly, coarse aggregates are placed into the formwork and grout is applied to fill in the voids. Secondly, the ratio of coarse aggregates in the mix proportion of PAC is higher than that in normal concrete. Typical value is about $60 \%$ as compared with $40 \%$ in normal concrete [5]. As coarse aggregates are preplaced first, they can occupy $60 \%$ to $70 \%$ of the total volume. In other words, only $30 \%$ to $40 \%$ of the total volume of grout is needed on-site. This substantially reduces the wet trades and exploitation of machinery and equipment on-site. Since coarse aggregates are not involved in the mixing process, PAC is environmental friendly with lesser consumption of energy. With a higher content of aggregates, PAC reduces the use of cement by $20 \%$ to $30 \%$ [6]. This reduction in cement also minimizes temperature rise in PAC.

Engineering properties of PAC, including its stress-strain relationship, is governed by the properties of coarse aggregates [7]. Applied stress is received by the skeleton of coarse aggregates and transferred to the hardened mortar [8]. Crushed aggregates showed better compressive strength then rounded aggregates, due to its rough surface, enhancing the mechanical interlock in between the aggregates and the grout $[9,10]$. However, the void ratio also increases, resulting in higher consumption of grout per concrete volume. Well-graded aggregates are recommended to minimize these voids. The void content can be reduced to as low as $25 \%$ of total volume by combining coarse aggregates with two different grading such as $12 \mathrm{~mm}$ and $38 \mathrm{~mm}$ and $200 \mathrm{~mm}$ and $250 \mathrm{~mm}$ [11]. Grout fluidity also affects the void content, as it may impede the grouting process. Dimensions through which the grout will pass is determined by the minimum size of the coarse aggregates used. Generally, the smallest size of coarse aggregates should be at least four times larger than the largest size of fine aggregates [11].

In the past, different sizes of coarse aggregates were suggested. Earlier, the recommended size of coarse aggregates in PAC was $38 \mathrm{~mm}$ [12]. The main advantage of being able to use larger size coarse aggregates is a reduction in the cost of crushing. Coarse aggregates smaller than $20 \mathrm{~mm}$ were suggested to be eliminated as they may interrupt the grout flow. Neville proposed the use of coarse aggregates of sizes smaller than $38 \mathrm{~mm}$, with the aggregates being gap-graded and of multiple sizes [13]. Later, the minimum size of coarse aggregates of $10 \mathrm{~mm}$ was suggested by Orchard [14]. However, the grouting process and the grout determine the minimum size of the coarse aggregates used or vice versa [3]. 
In this study, single graded aggregates of different sizes were used. It aims to investigate the effect of coarse aggregate size and grouting process on PAC using a suitable grout. Mix proportion of grout for general application of PAC is also recommended.

\section{Methodology}

In this study, different mix proportions of grout were examined to produce a grout mix suitable for the production of PAC. Efflux time of grout along with compressive strength for both 7 days and 28 days were tested. Grout mix with desired flowability and strength was used to produce PAC by both pumping and gravity process. Four different sizes of coarse aggregates were considered i.e. $45 \mathrm{~mm}, 37 \mathrm{~mm}, 20 \mathrm{~mm}$ and $14 \mathrm{~mm}$. Variation in compressive strength against coarse aggregate size and grouting process was evaluated. Excess voidage and resistance to chloride ion penetration was also investigated.

\subsection{Materials and grout mix design}

Ordinary Portland Cement of Type I conforming to ASTM C150 was used. Natural river sand having a specific gravity of 2.65 and fineness modulus of 2.41 was used as fine aggregates. Locally available crushed granite sieved to different sizes were used as coarse aggregates. The superplasticizer used was ADVA 109.

Two sand to binder (S/B) ratios were considered, namely 0.5 and 1.0. With further increase in $S / B$, the grout became denser and non-flowable. Water to binder (W/B) ratios varied between $0.33,0.37$ and 0.42 . Further increase in the amount of water led to segregation. Superplasticizer (SP) was applied at $0.5 \%$ by weight of binder (B). Table 1 shows the mix proportion of different grouts. Fig. 1 shows the void ratios for different sizes of aggregates used, which was estimated as per ASTM C 29 [15].

Table 1: Grout mix design.

\begin{tabular}{|c|c|c|c|c|}
\hline $\begin{array}{c}\text { Mix } \\
\text { number }\end{array}$ & Mix ID & S/B & W/B & SP by weight of B \\
\hline 1 & S0.5W0.33 & 0.5 & 0.33 & $0.5 \%$ \\
\hline 2 & S0.5W0.37 & 0.5 & 0.37 & $0.5 \%$ \\
\hline 3 & S0.5W0.42 & 0.5 & 0.42 & $0.5 \%$ \\
\hline 4 & S1W0.33 & 1.0 & 0.33 & $0.5 \%$ \\
\hline 5 & S1W0.37 & 1.0 & 0.37 & $0.5 \%$ \\
\hline 6 & S1W0.42 & 1.0 & 0.42 & $0.5 \%$ \\
\hline
\end{tabular}

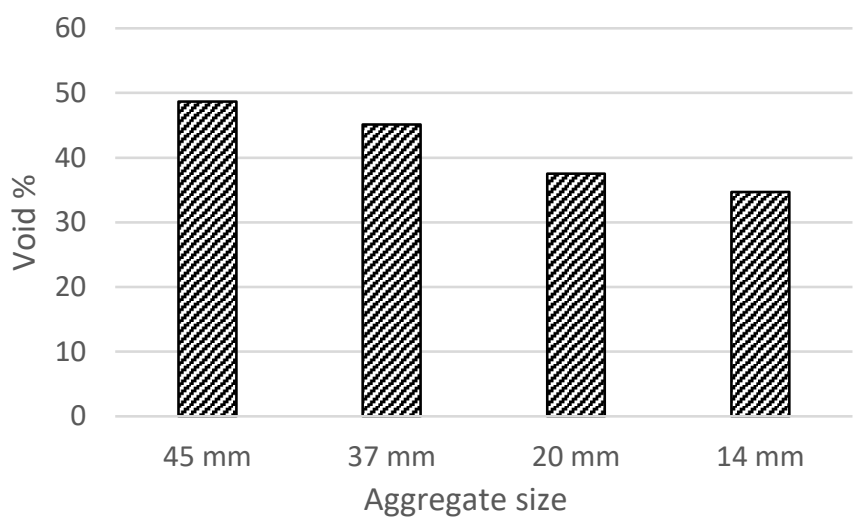

Fig. 1: Void (\%) in-between aggregates. 


\subsection{Selection of mix proportion of grout}

Flow cone test was performed as per ASTM C 939 [16] to determine the grout consistency. Fig. 2 shows the results of flow cone tests. With the increase in W/B ratio, the time of efflux decreased. When S/B ratio equals to 1, the time of efflux was longer as it made the grout denser. Efflux time for Mix ID S1W0.37 and S1W0.42 could not be measured due to inconsistency of flow and excessive segregation respectively. Grout with an efflux time of $22 \pm 2$ seconds is usually considered satisfactory for works such as walls and structural repairs [11]. Based on the above, Mix ID S0.5W0.37 was found to be most satisfactory mix with a flow cone value of 21.26 seconds.

Fig. 3 shows the 7 days and 28 days compressive strength of the grout tested as per ASTM C 942 [17]. With the increase in W/B ratio, for the same S/B ratio, both 7 days and 28 days compressive strength decreases. In case of mix ID S0.5W0.33 and S1W0.33, for the same W/B ratio, increase in S/B ratio did not have any significant effect on the compressive strength. For W/B ratio of 0.37, with the increase in S/B ratio, the compressive strength decreases. This can be attributed to the fact that with the increase in S/B and W/B ratio, the volume of binder decreases by a fair amount.

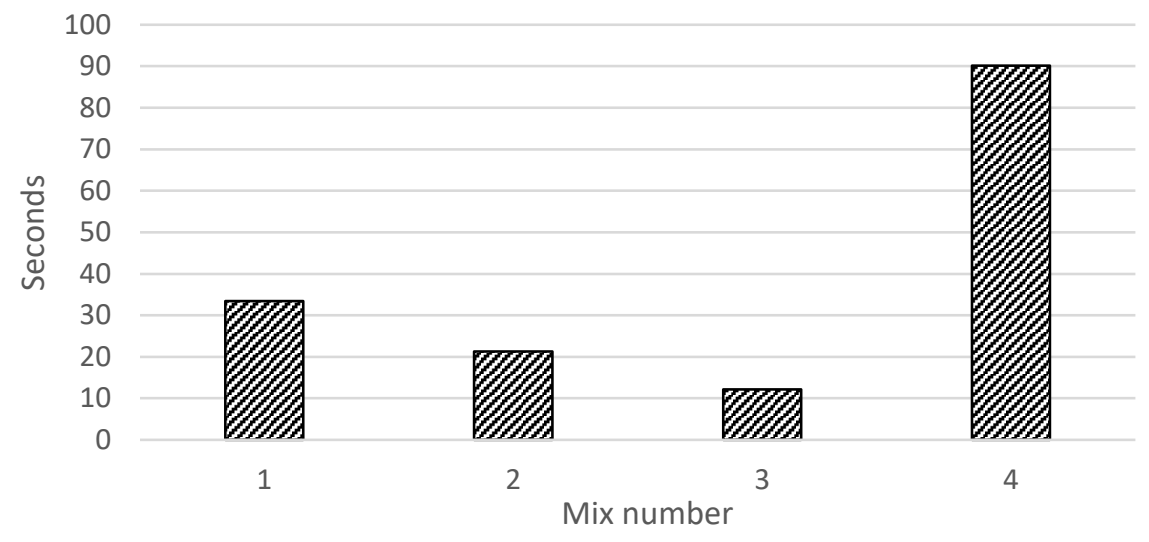

Fig. 2: Grout efflux time.

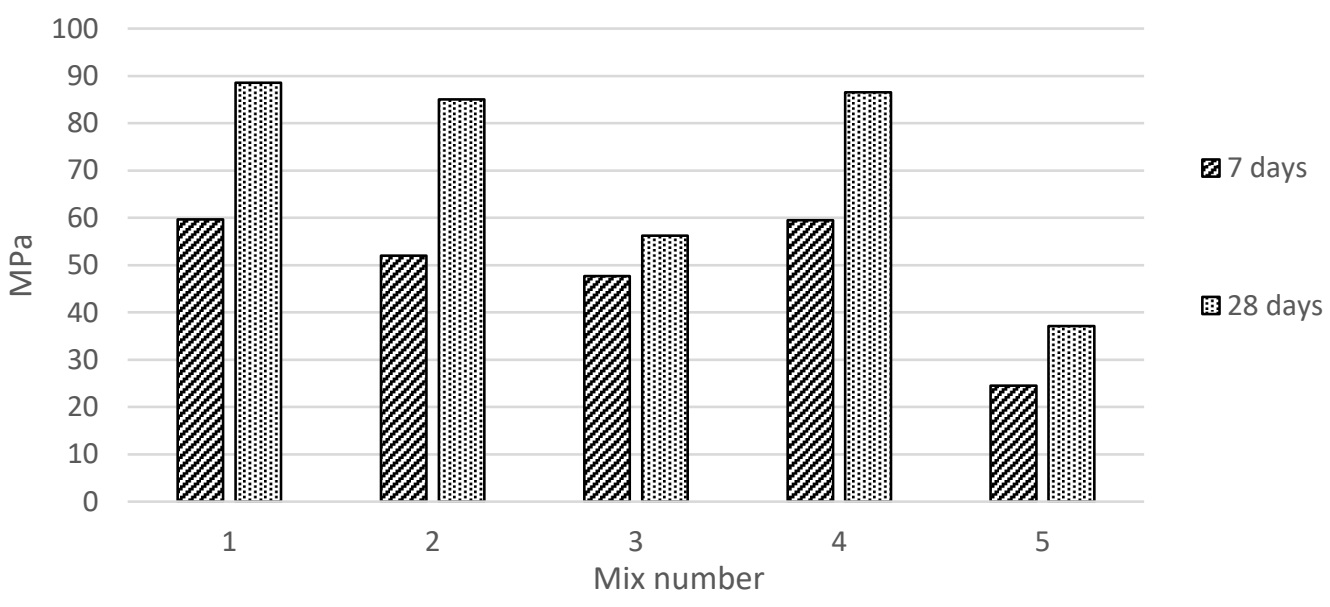

Fig. 3: Grout compressive strength.

From the flow cone and compressive strength results, mix ID S0.5W0.37 was selected with optimal performance at efflux time and both 7 days and 28 days compressive strength. Hence, mix ID S0.5W0.37 was applied to subsequent study.

\subsection{Specimens and tests}


Transparent acrylic moulds were used for preparation of specimens. Hollow cylinders of $150 \mathrm{~mm}$ internal diameter were cut to $300 \mathrm{~mm}$ length and into two halves parallel to its length for easy demoulding. Acrylic square plates of sufficient thickness were used to form the base. The halves of cylinders along with the plates at the base were assembled and glued together. To further increase the strength of the cylindrical moulds, metal strips were braced along the perimeter. For gravity process, grout was poured from the top, whereas for the pumping process, grout was pumped from the base. Valves were used to regulate and control the flow of grout. Fig. 4 shows the setup of (a) Cylindrical moulds, (b) Cylindrical moulds with aggregates, (c) grouting via pumping process. High-pressure portable cement grout pump with a flow up to $8 \mathrm{~L} / \mathrm{min}$ was used to perform the pumping process. For the estimation of excessive voidage and ability to resist chloride ion penetration, the cylindrical specimens of $150 \mathrm{~mm}$ diameter were cast into a slab. After 7 days, when the slab hardened, $100 \mathrm{~mm}$ diameter cores were drilled out from cylinders embedded into the slab as in shown Fig. 4 (d).

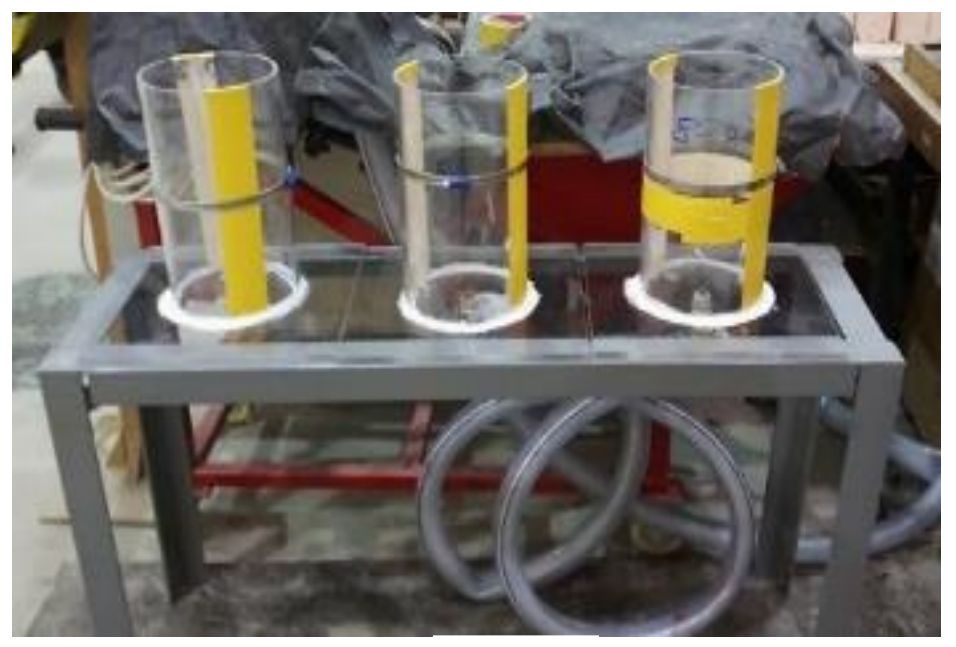

(a)

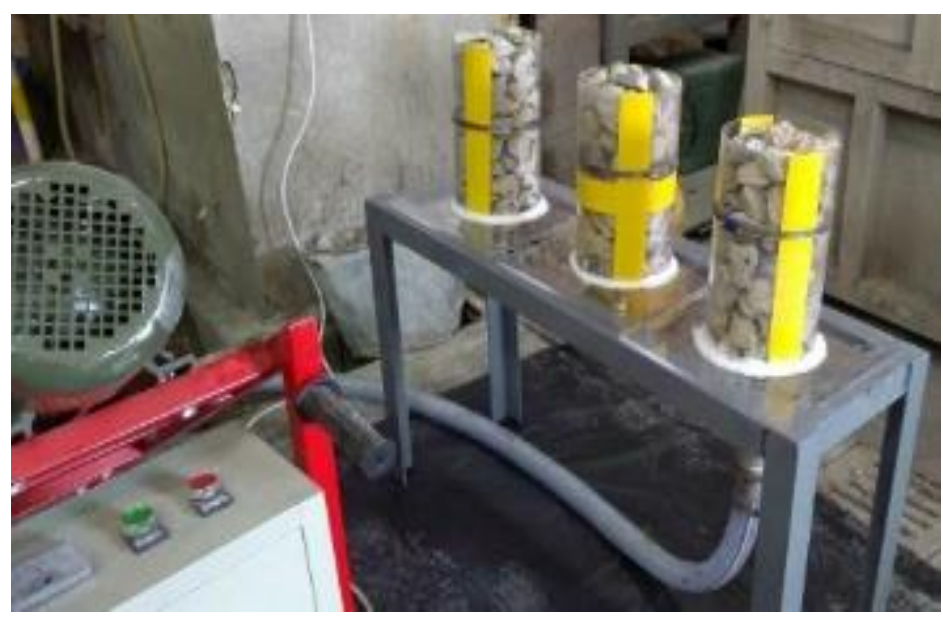

(c)

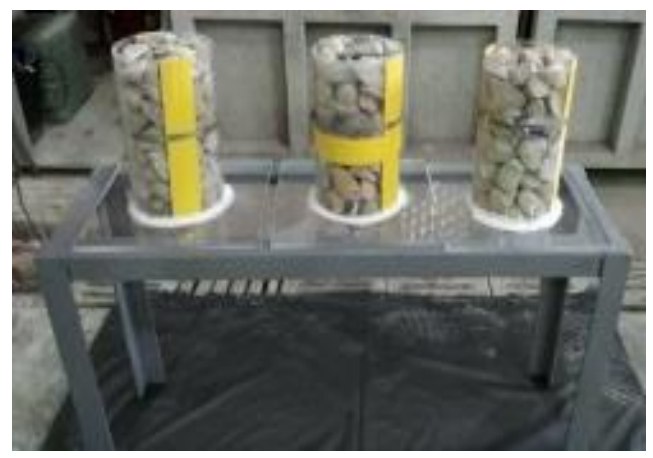

(b)

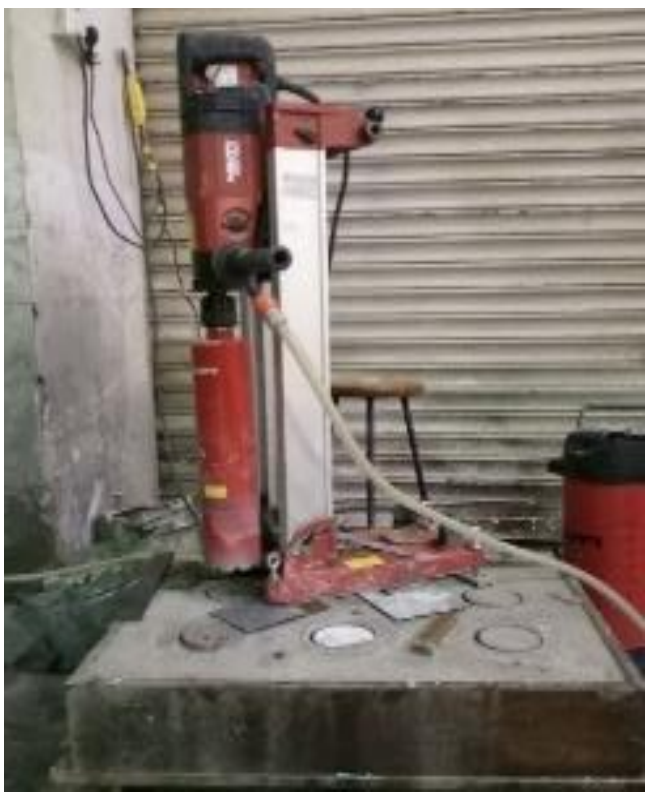

(d)

Fig. 4: Experimental setup.

Conventional concrete (concrete produced by traditional mixing) was also produced for comparison, using $20 \mathrm{~mm}$ sized coarse aggregates. The amount of cement and water in both PAC and conventional concrete were kept nearly the 
same. The only difference was coarse aggregates to fine aggregates ratio. The proportion of coarse aggregates was higher in PAC. A similar comparison was done in the past as well [4].

\section{Results and discussions \\ 3.1. Voidage of PAC}

Excess voidage is referred to the pockets of entrapped air in between the concrete specimens. $100 \mathrm{~mm}$ diameter cores were collected from PAC specimens for estimation of excessive voidage as per BS 1881: Part 120 [18]. Fig. 5 shows excessive voidage of PAC (X mm, G/P, Y\%), where, $\mathrm{X}$ is the aggregate size, $\mathrm{G}$ and $\mathrm{P}$ stand for gravity process and pumping process respectively, and $\mathrm{Y}$ is the excessive voidage.

For 45 to $20 \mathrm{~mm}$ aggregates, voidage was $1.50 \%$ and $0.50 \%$ for gravity process and pumping process respectively. When the aggregate size was reduced to $14 \mathrm{~mm}$ for the gravity process, the voidage increased to $3 \%$. However, the pumping process resulted in lower voidage. As the grout was pumped under pressure to fill up aggregate channels, it resulted in more efficient filling up of the voids.
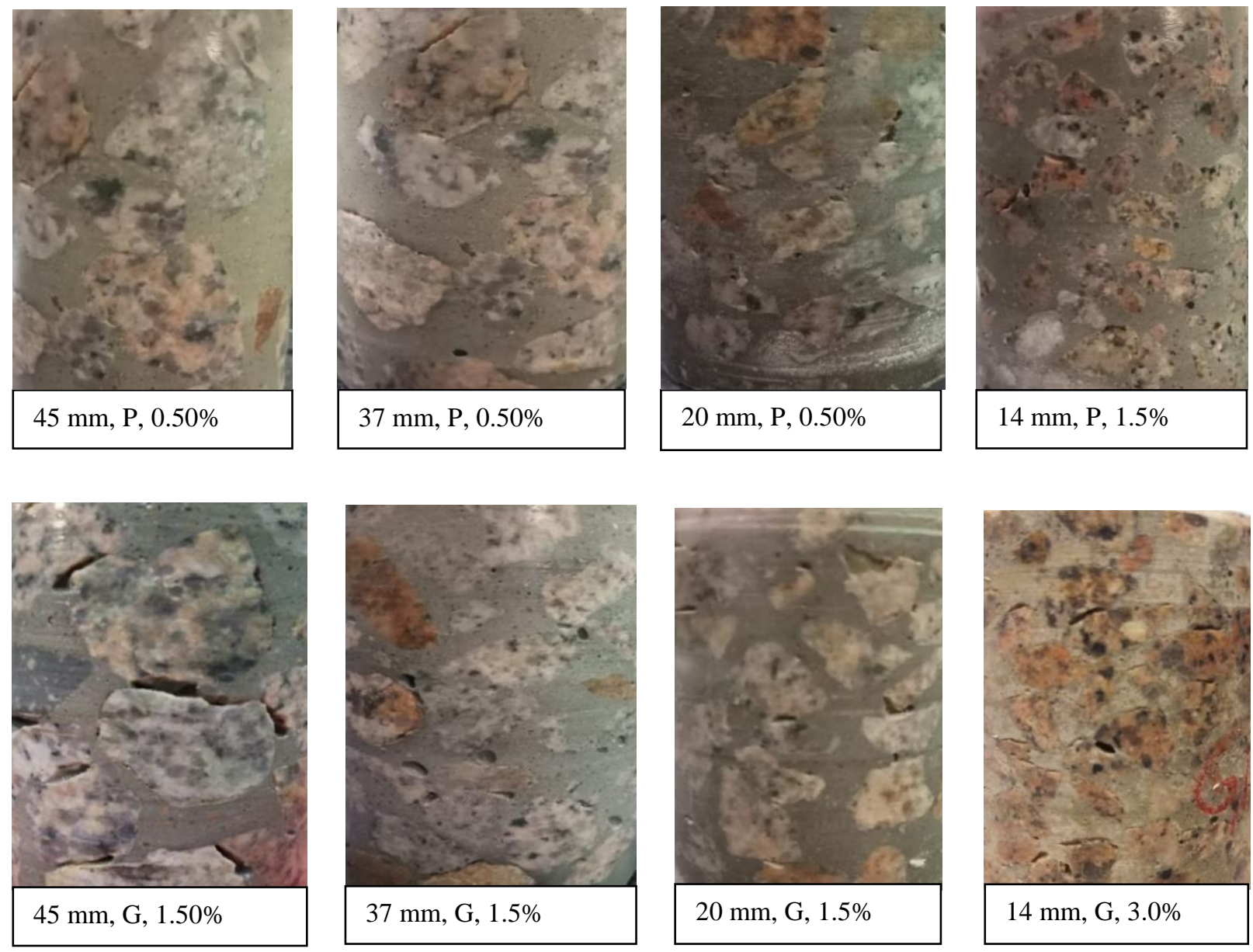

Fig. 5: Excessive voidage in PAC.

\subsection{Compressive strength}

Compressive strength of PAC produced by both gravity and pumping process was investigated as per ASTM C 39 [19]. Average of three cylindrical specimens of $150 \mathrm{~mm}$ diameter and $300 \mathrm{~mm}$ height was considered.

As shown in Fig. 6, with the decrease in aggregate size, compressive strength reached its peak value at 20 mm aggregate size. For aggregate sizes at $45 \mathrm{~mm}$ and $37 \mathrm{~mm}$, the difference was not significant. However, $20 \mathrm{~mm}$ aggregate size showed an increase in compressive strength by $25 \%$ to $30 \%$. This could be attributed to higher contact area between aggregates 
resulting in efficient stress transfer through the aggregate skeleton and better mechanical interlocking in between the aggregates. Reducing the aggregate size to $14 \mathrm{~mm}$ resulted in a decrease in compressive strength as the channels through which the grout flows became narrower, impeding the flow of grout. Hence, optimum aggregate size was found to be $20 \mathrm{~mm}$.

For PAC with coarse aggregates at size $20 \mathrm{~mm}$ and above, compressive strength of PAC produced by pumping and gravity process was not significant, as the voids between the aggregates were larger, allowing the grout to penetrate easily. PAC with aggregate size $14 \mathrm{~mm}$ produced by gravity process was found to have the highest void percentage (3\%) and the compressive strength was reduced by $17 \%$ than that of pumping process. Strength of concrete is greatly reduced by the presence of voids. $2 \%$ to $5 \%$ void can reduce concrete strength by $10 \%$ to $30 \%$ [13]. As the grout is injected under pressure during pumping process, air trapped in between the aggregates is forced out and thus efficiently fills in the voids. This ensures better performance in terms of both voidage and strength, especially when smaller size aggregates are used.

Conventional concrete was found to produce a compressive strength of $36 \mathrm{MPa}$ which was about $15 \%$ lower than that produced by PAC for the same size of aggregates used. This could be attributed to the point to point contact of coarse aggregates in PAC, leading in an efficient stress distribution system.

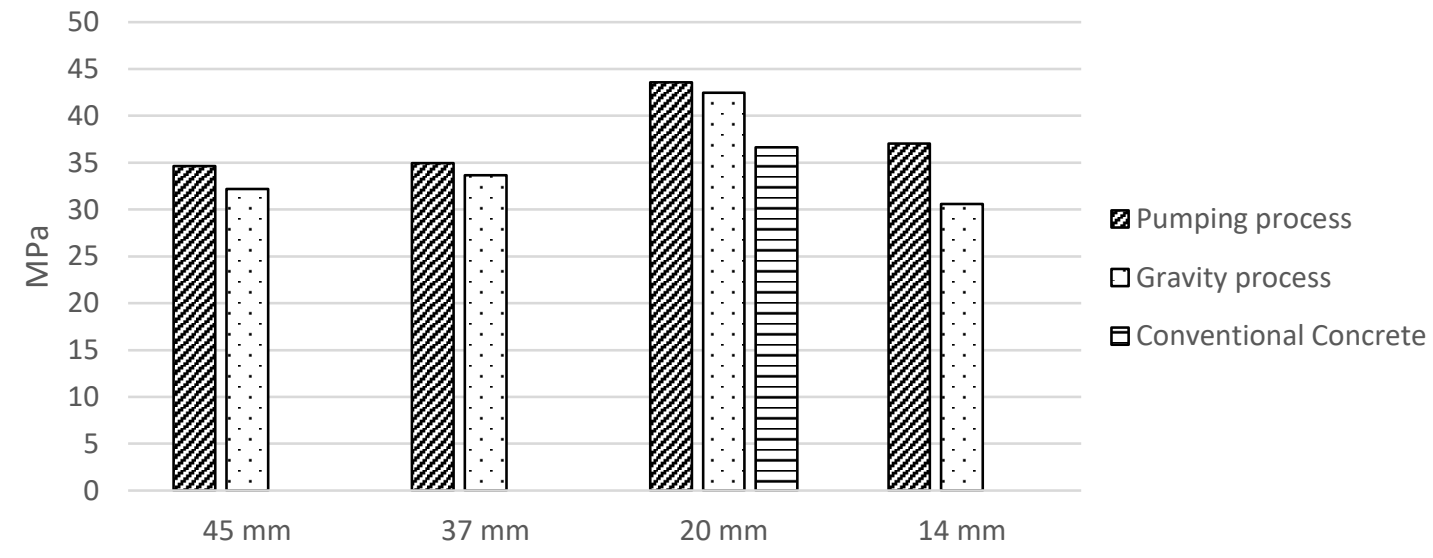

Fig. 6: 28 days compressive strength.

\subsection{Chloride Ion Penetration}

Chloride ion penetration test was carried out at 28 days from casting, as per ASTM C 1202 [20]. Fig. 7 shows the experimental setup of the experiment. The level of chloride ion penetration based on the charge passed, as per ASTM C 1202 is shown in Table 2.

As shown in Fig. 8, for aggregate sizes ranging from $37 \mathrm{~mm}$ to $14 \mathrm{~mm}$, the chloride ion penetrability was found to be moderate. PAC with $20 \mathrm{~mm}$ aggregates showed the lowest chloride ion penetrability. For $45 \mathrm{~mm}$ aggregate size, chloride ion penetration was higher. This can be attributed to that with larger aggregates, the amount of grout per surface area is large, providing a larger surface for the ions to pass. With the decrease in size of aggregates, the volume of grout in the specimen decreases. Charge passed was found to decrease with the decrease in aggregate size from $45 \mathrm{~mm}$ to 20 $\mathrm{mm}$. Chloride ion penetration increased with the reduction in size of aggregates to $14 \mathrm{~mm}$. This could be the result of high amount of air pockets entrapped in between the aggregates, resulting in an increase in its permeability. For all sizes of aggregates used, pumping process showed higher resistance to chloride ion penetration then gravity process. This is the result of excess voidage in PAC produced by gravity process.

As shown in Fig. 8, conventional concrete had similar amount of charge passing, indicating permeability comparable to PAC specimens. Hence, PAC was found to display compatible resistance to chloride ion penetration with that of conventional concrete. 
Table 2: Chloride ion penetrability based on charge passed.

\begin{tabular}{|l|l|}
\hline Charge Passed (coulombs) & Chloride Ion Penetrability \\
\hline$>4,000$ & High \\
\hline $2,000-4,000$ & Moderate \\
\hline $1,000-2,000$ & Low \\
\hline $100-1,000$ & Very Low \\
\hline$<100$ & Negligible \\
\hline
\end{tabular}

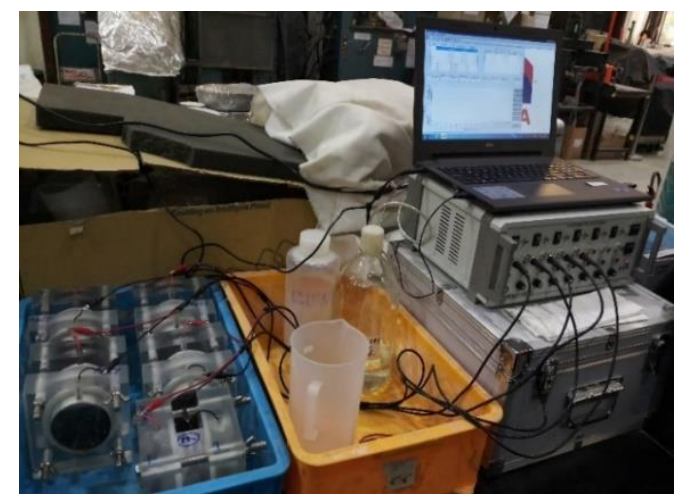

Fig. 7: Experimental setup for chloride ion penetration.

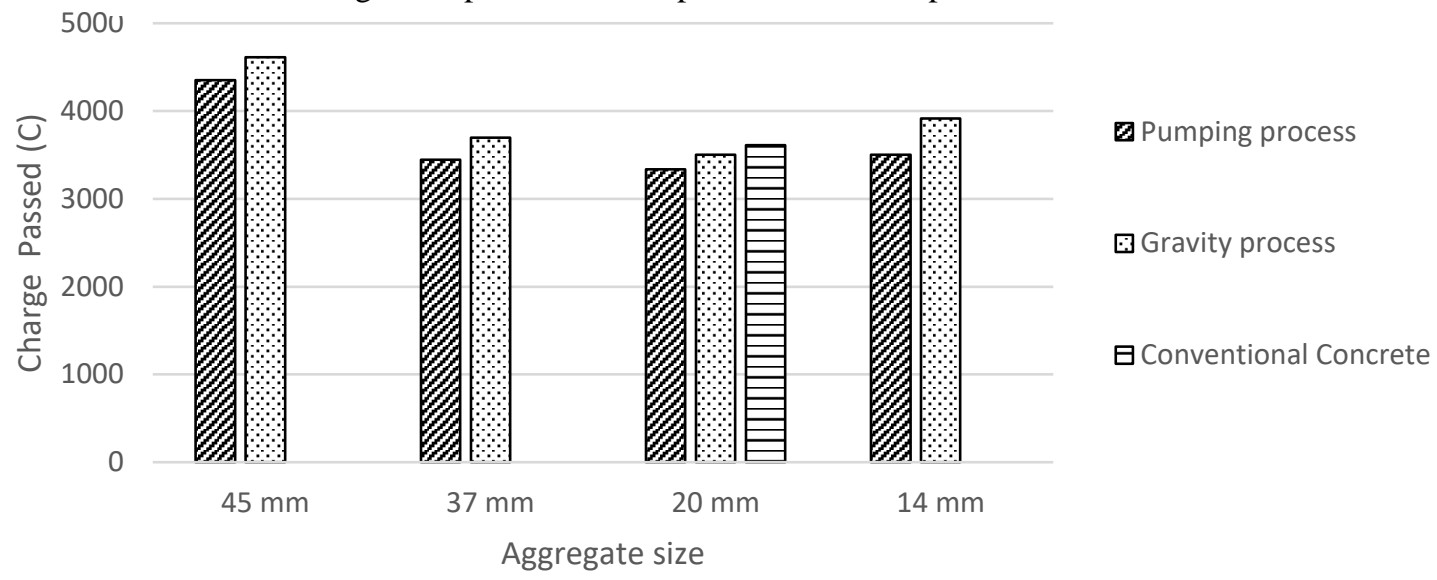

Fig. 8: Charge passed through concrete during chloride ion penetration.

\section{Conclusions}

- Mix proportion of grout plays a vital role in the grouting process. In this case, grout having W/B=0.37 and $\mathrm{S} / \mathrm{B}=0.5$ was found to provide an optimum performance. Low W/B ratio (0.37) contributes towards acceptable strength and low $\mathrm{S} / \mathrm{B}$ ratio $(0.5)$ helps in providing a good flowability.

- $20 \mathrm{~mm}$ aggregate size was found to be the optimum size. For $14 \mathrm{~mm}$ aggregates, the passage for the grout to flow through is smaller which resulted in inefficient filling of voids and higher excess voidage leading to lower compressive strength.

- The chloride ion penetration results followed a similar trend to that of compressive strength. PAC with higher compressive strength showed higher resistance to chloride ion penetration. Larger sized aggregates had more grout content resulting in higher chloride penetration.

- Gravity process is suggested to be used for a minimum aggregate size of $20 \mathrm{~mm}$. However, for coarse aggregates lower than $20 \mathrm{~mm}$, grouting should be done implementing special pumping techniques to ensure efficient penetrability of the grout through the aggregates. 


\section{Acknowledgements}

The authors acknowledge the financial support provided by the Hong Kong Polytechnic University. The authors are grateful to the technical support provided by the laboratory of the Department of Civil and Environmental Engineering.

\section{References}

[1] M. Marke and A. Marke, "Comparative evaluation of the flexural strength of concrete and colcrete," Nigerian Journal of Technology, vol. 29, no. 1, pp.13-22, 2010.

[2] Z. Strzelecki and Z. Kohutek, "Research on possible application of 'polcrete' concrete for supporting long openings (in Czech)," International Journal of Rock Mechanics and Mining Sciences \& Geomechanics Abstracts, vol. 18, no. 4, pp. 73, 1981.

[3] M. Najjar, "Innovating Two-Stage Concrete with Improved Rheological, Mechanical and Durability Properties," Ph.D. dissertation, Dept. Civil and Environmental Engineering, The University of Western Ontario, Ontario, 2016.

[4] A. Abdul Awal, "Failure Mechanism of Prepacked Concrete," Journal of Structural Engineering, vol. 114, no. 3, pp. 727-732, 1988.

[5] M. Najjar, A. Soliman and M. Nehdi, "Critical overview of two-stage concrete: Properties and applications," Construction and Building Materials, vol. 62, pp. 47-58, 2014.

[6] A. Nowek, P. Kaszubski, H. Abdelgader and J. Górski, "Effect of admixtures on fresh grout and two-stage (pre-placed aggregate) concrete," Structural Concrete, vol. 8, no. 1, pp. 17-23, 2007.

[7] H. Abdelgader and J. Górski, "Influence of grout proportions on modulus of elasticity of two-stage concrete," Magazine of Concrete Research, vol. 54, no. 4, pp. 251-255, 2002.

[8] H. Abdelgader, "Effect of the quantity of sand on the compressive strength of two-stage concrete," Magazine of Concrete Research, vol. 48, no. 177, pp. 353-360, 1996.

[9] H. Abdelgader, "How to design concrete produced by a two-stage concreting method," Cement and Concrete Research, vol. 29, no. 3, pp. 331-337, 1999.

[10] J. O'Malley and H. Abdelgader, "Investigation into viability of using two-stage (pre-placed aggregate) concrete in Irish setting," Frontiers of Architecture and Civil Engineering in China, vol. 4, no. 1, pp. 127-132, 2010.

[11] P. Stodola, D. Akers, J. Bennett Jr, A. Cheff, T. Clapp, J. Cope and D. Green. "Guide for the Use of Preplaced Aggregate Concrete for Structural and Mass Concrete Applications," ACI Materials Journal, vol. 88, no. 6, 1992.

[12] S. Champion and L. Davis, "Grouted concrete construction," Reinf. Concrete Rev., 1958.

[13] A. Neville, Properties of concrete, $4^{\text {th }}$ Ed, London Pearson Education Limited, 443(846), London, 1995.

[14] D. Orchard, Concrete Technology, London: Applied Science Publishers Ltd, vol. 2, 1973.

[15] ASTM, C29. "Standard test method for bulk density ("unit weight") and voids in aggregate," ASTM International, 2009.

[16] ASTM C 939. "Standard test method for flow of grout for preplaced-aggregate concrete (flow cone method)," ASTM International, 2002.

[17] ASTM C 942. "Standard test method for compressive strength of grouts for preplaced-aggregate concrete in the laboratory," ASTM International, 2008.

[18] BS-1881:120. Testing concrete part 120. "Method for determination of the compressive strength of concrete cores," London: British Standard Institution, 1983.

[19] ASTM C 39. "Standard test method for compressive strength of cylindrical concrete specimens," ASTM International, 2005.

[20] ASTM C 1202. "Standard test method for electrical indication of concrete's ability to resist chloride ion penetration," ASTM International, 2012. 